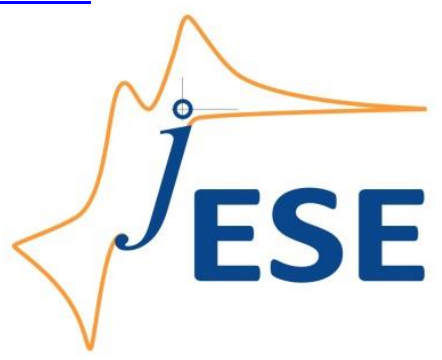

Open Access : : ISSN 1847-9286

www.jESE-online.org

Original scientific paper

\title{
Development and performance of hybrid coatings on aluminium alloy
}

\author{
Makanjuola Oki ${ }^{1,2, 凶}$, Adeolu Adesoji Adediran ${ }^{1}$, Saheed Olayinka $^{1}$, \\ Oyeyemi Ogunsola ${ }^{1}$
}

${ }^{1}$ Department of Mechanical Engineering, College of Science and Engineering, Landmark University, Omu-Aran, Kwara State, Nigeria

${ }^{2}$ Department of Mechanical Engineering, College of Science and Engineering, Landmark University, Omu-Aran, Kwara State, Nigeria

${ }^{凶}$ Corresponding author: E-mail: makanjuola.oki@Imu.edu.ng; Tel.: +2347061135549

Received: September 26, 2016; Revised: January 26, 2017; Accepted: July 21, 2017

\begin{abstract}
From gravimetric studies, hybrid nano-coatings, based on permanganate/fluoride/glycerol conversion coating solutions formed on aluminum alloy by immersion procedures developed rapidly at a rate which decreased with time of treatment and was about $16 \mathrm{mg}$ in weight after a period of three minutes. The morphology of the coating during scanning electron microscopic (SEM) examinations revealed randomly shaped coating materials with mud cracking patterns, characteristics of dried out coatings derived from gel-like materials. Analyses of the coating using EDX attachment in the SEM showed that it was composed essentially of aluminum, oxygen and manganese compounds, probably hydrated. The corrosion resistance of the coating out-performed 'bare' aluminum alloy specimens exposed to natural environment and $1 \mathrm{M}$ sodium chloride solution. The coating improved the paint adhesion characteristics of the substrate aluminum alloy.
\end{abstract}

\section{Keywords}

adhesion, SEM/EDX, permanganate, glycerol, morphology, pitting

\section{Introduction}

Automobile customers' demands for higher performance, more luxury and safety features signaled the development of lightweight and hence more energy efficient vehicles led to the introduction of aluminum and its alloy to achieve considerable weight reductions with no losses in strength and stiffness. However, the changes in choice of material and body structure presented significant challenges with respect to methods of joining and finishing of the automobiles. From a technical point of view, conversion coatings offer several advantages such as improved corrosion 
resistance and adhesion of paint and/ adhesives to aluminum and its alloys used in the automotive industry. To attain a long service life under demanding conditions, pre-treatment of the aluminum and its alloys before any fabrication of parts is an extremely important factor. The successful use of chromate conversion coating in the aluminum finishing industry in the last five decades demonstrated that superior strength can be acquired, even when the coated structure is exposed to corrosive environments [1]. However, several protocols in the last two decades have limited the use of carcinogens like volatile organic compounds (VOCs) and the chromates. In view of this shortcoming several authors [2-5] have researched into alternatives to chromates based on transition metal compounds without much success in terms of corrosion resistance superiority of the chromates. Although there are claims in the literature that some composite precursor compounds such as Permanganate/Molybdate [6] conversion coating has superior corrosion resistance to chromate and Molybdate conversion coatings separately, its application in the high technical end of the metal finishing industry may yet be in its infancy. Other claimed success is the permanganate conversion coating developed on Magnesium alloy [7]. The coating which was developed from an acidic bath is termed to be nearly crack-free and its corrosion resistance was markedly better than the untreated alloy. However, permanganate coatings have been described by Hughes et al.[8], as a promising replacement for chromates in the aerospace industry. In their findings, the coating is generally about 50-70nm in thickness and it was said to be essentially of $\mathrm{MnO}_{2}$ in its outermost regions with a composite of Al-Mn oxides predominantly at the metal/coating interphase. As the search for alternatives to chromates proceeds far and wide, other researchers are looking into sol-gel formulations such as aluminum-based sol-gel materials by Oubaha et al. [9], and silanol-based nanocomposite by Gonzalez et al [10] with much success recorded in terms of improved paint adhesion characteristics which compared favorably with the chromates. Nonetheless, some of these formulations and processes have been patented [11] but their applications have been limited to the lower technical end of the metal finishing markets while in the high technical end as in the aerospace industry as well as military hardware, chromates are still preferentially employed [12]. In order to make the use of chromates more acceptable to the metal finishing industries, a none-rinse chromate formulation was developed. Addition of organic compounds containing hydroxyl groups to chromate baths modified the surface features of the traditional coating where the usual mudcracking was obliterated and it became unnecessary to give a final water rinse to objects treated in such baths [13]. In addition, the coatings dried faster than the traditional chromate coating thus achieving reduction in cost of production. Hence, from environmental safety and costs perspectives, the formation and process pushed the hybrid coating a notch higher than the traditional chromate coating and process in terms of lower carbon foot print.

In view of the limited successes encountered in the search for viable alternatives to chromate, the current investigation, examined permanganate, containing $\mathrm{Mn}$, with variable valences similar to the chromate as a precursor conversion coating material of interest which may also act as a cathodic inhibitor at breached areas of the coating where the substrate may be exposed albeit, transiently.

\section{Experimental}

Spade like electrodes were made from sheet of aluminum alloy AA8000. These electrodes were etched in $10 \%$ sodium hydroxide solution, rinsed in water prior to de-smutting in $50 \% \mathrm{v} / \mathrm{v}$ nitric acid solution for three minutes each and then rinsed in water. Electrodes, prepared in the afore mentioned manner, were immersed in a solution of $4 \mathrm{~g} / \mathrm{I} \mathrm{KMnO}_{4}, 1 \mathrm{~g} / \mathrm{l} \mathrm{NaF}$ and $5 \mathrm{ml} / \mathrm{l}$ glycerol made up to 1 liter of water, at $30^{\circ} \mathrm{C}$ for several periods of time ranging from 30 seconds to 600 seconds. 
Three separate specimens were treated in the conversion coating solution for each period of time. Thereafter the mean changes in weights were recorded for each pretreatment time. The $\mathrm{pH}$ of the solution was 7.9 as obtained from JENWAY, Model $3505 \mathrm{pH}$ Meter. All chemicals used were of laboratory or industrial grades. Some specimens treated for various times in the manganate/fluoride/glycerol coating solution were examined in scanning electron microscope, Phenom proX SEM, model MVE0224651193, operated at 15keV. The elemental compositions of the coatings were obtained from the EDX attachment in the microscope. Specimens treated for 180 seconds in the coating solutions were exposed in upright positions to the natural environment in the North Central part of Nigeria for $500 \mathrm{~h}$ with untreated aluminum alloy specimens exposed likewise. These were visually examined regularly. Some other set of specimens were likewise treated in the coating solutions for 180 seconds. These were further coated with a nitrocellulose lacquer by immersing the spade like end of the pretreated specimens as near vertical as possible in $100 \mathrm{ml}$ of the lacquer for 60 seconds and withdrawn as immersed, allowed to dry for $24 \mathrm{~h}$ prior to further examination. Untreated aluminum and pretreated specimens as well as those over coated with lacquer were cross-scratched, using Japanese industrial testing method [14] prior to exposure to near neutral $1 \mathrm{M} \mathrm{NaCl}$ solution for $170 \mathrm{~h}$. After the exposure period, transparent cellophane adhesive tapes were firmly applied on each of the specimens. The tapes were subsequently rapidly pulled from the substrates. The surfaces were examined to appraise the mode(s) of coating failure by optical microscopy and in the SEM with analyses performed in the EDX attachment of the SEM.

\section{Results and discussion}

\section{Coating development}

From visual examinations, the specimens immersed in the permanganate/fluoride/glycerol coating solution showed changes in color from the initial lustrous metallic appearance to progressively dark golden yellow colorations as time of immersion progressed. On surface value, this implied formation and development of coating on aluminum in the conversion coating solution. The formation and development of permanganate coating on aluminum probably followed "the substrate activation/coating materials deposition" model reported for chromate conversion coatings $[15,16]$ which will involve the activation of aluminum by fluoride species in solution thus,

$$
\mathrm{Al} \stackrel{\mathrm{F}^{-}}{\longrightarrow} \mathrm{Al}^{3+}+3 \mathrm{e}^{-}
$$

The 3 electrons generated during the activation of aluminum, an anodic reaction, are then taken up by permanganate species which are reduced to manganate species in the cathodic half of the redox reaction. Another school of thought has it that though thinning of the oxide layer on aluminum does take place; a favorable anodic reaction is the reformation of aluminum oxide which allows for electron tunneling. These Mn (IV) species, at their established equilibrium constant, are deposited as probably hydrated oxide/hydroxides and may be contaminated with permanganate in the coating solution and aluminum species generated in equation (1). These species may as well be adsorbed and/or occluded within the developing coating.

$$
2 \mathrm{H}_{2} \mathrm{O}+\mathrm{MnO}_{4}^{-}+3 \mathrm{e}^{-} \rightarrow \mathrm{MnO}_{2}+4 \mathrm{OH}^{-}
$$

Figure 1 displays the coating weight versus time of immersion for aluminum specimens in permanganate conversion coating bath. The rate of coating growth was fast initially, however, the rate decreased with increase in immersion time. 


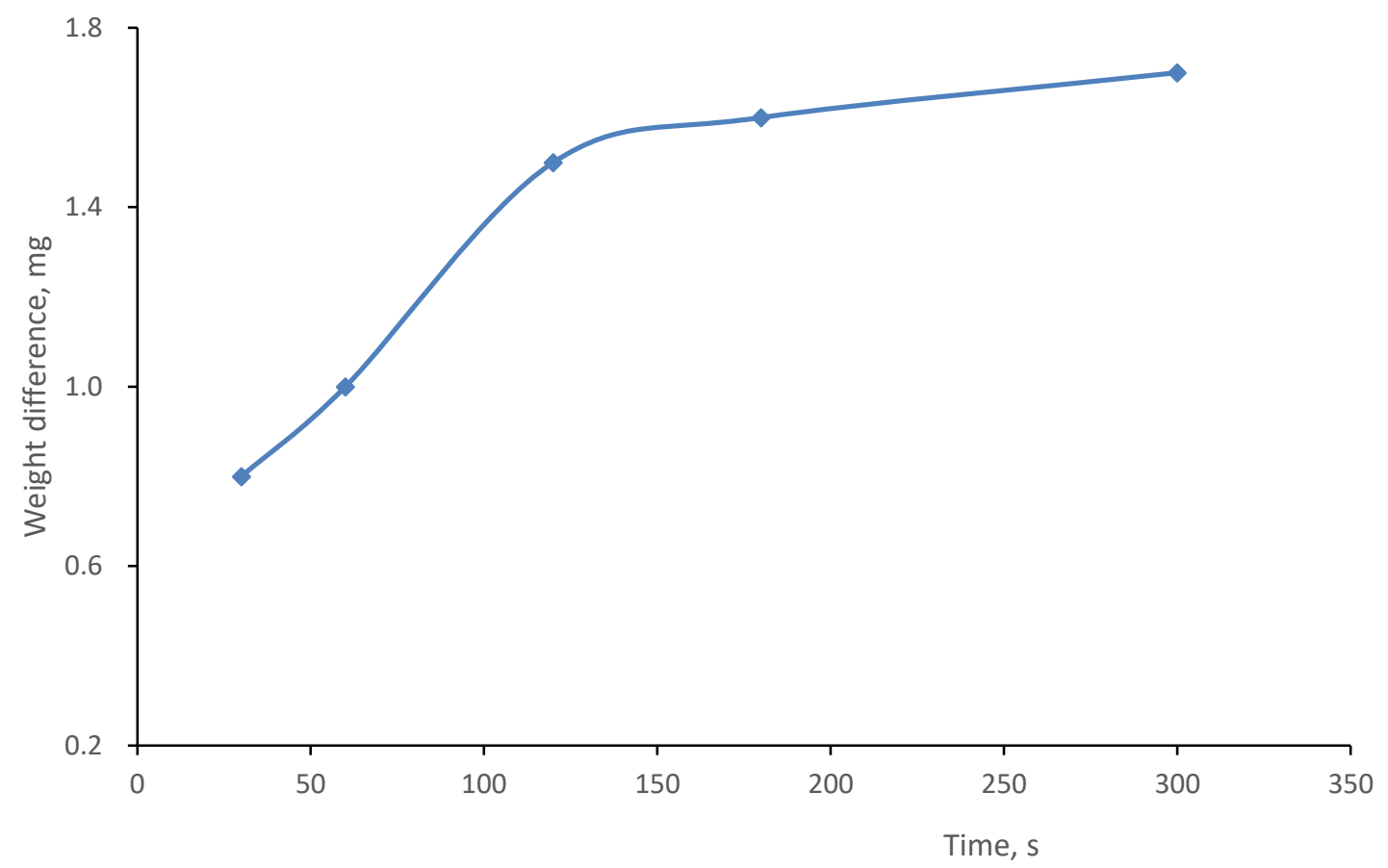

Figure 1. Graph of coating weight against time of immersion in Manganate/fluoride/glycerol solution at $30^{\circ} \mathrm{C}$

This was envisaged as the initial coating materials deposited on the specimens will initially constitute barriers to further coating growth $[17,18]$. However, as espoused by $[15,16,19]$ and others, further coating growth beyond the initial rapid deposition of coating materials will proceed at the metal coating interface with the creation of pathways within the coating. Thus, coating solution species will come in contact with the substrate although at a reduced rate with continued growth of the coating.

\section{Surface morphology and composition}

The surface morphology for the specimen treated for 180 seconds in the permanganate coating bath is displayed in Fig. 2 and it portrays a typical surface morphology for specimens treated in the permanganate coating bath for various times.

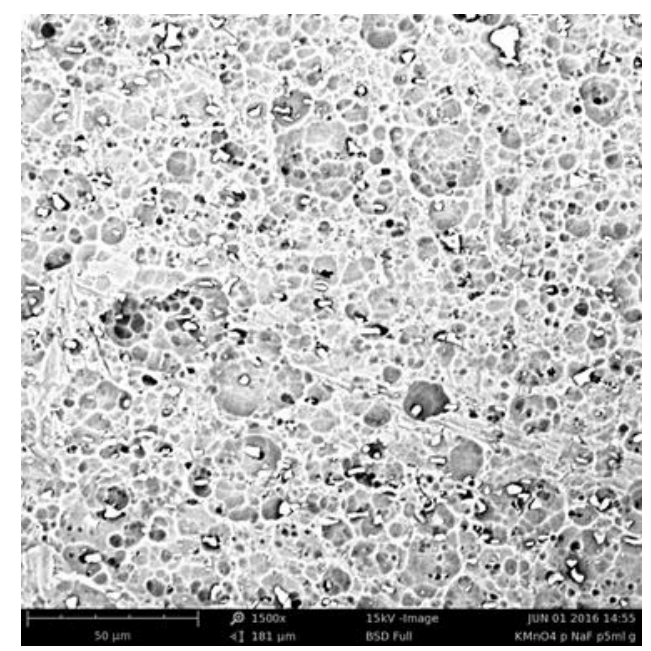

Figure 2. SEM micrograph of aluminium specimen treated for 180 seconds in Manganate/fluoride/glycerol conversion coating bath at $30^{\circ} \mathrm{C}$ 
The surface is comprised of variously shaped coating materials formed along with mud-cracking patterns derived from shrinkage stresses associated with drying out of gel-like materials. Such randomly shaped and cracked surface features have been suggested to be anchor sites for subsequently applied organic coatings with attendant improvement in paint adhesion characteristics of conversion coated substrates [20]. However other researchers believed that in addition to these anchor sites, bonds formation between organic coatings and species in conversion coatings play significant roles in the improvement of paint adhesion properties of conversion coated substrates [21]. Also, in an earlier study it was suggested that roughness at microscopic level imparted on conversion coated surfaces played added significant roles in adhesion improvement properties of conversion coated aluminum substrates [22].

The coating materials as revealed through analysis with the EDX attachment in the SEM are composed of $\mathrm{Mn}, \mathrm{Al}$ and oxygen compounds, Fig. 3, probably hydrated as the materials were derived from gel-like materials. This is in agreement with the findings of Hughes et al. [8] who suggested two diffused layers of coatings with the interior being richer in Al-Mn hydrated oxides and an outer region rich in $\mathrm{MnO}_{2}$.

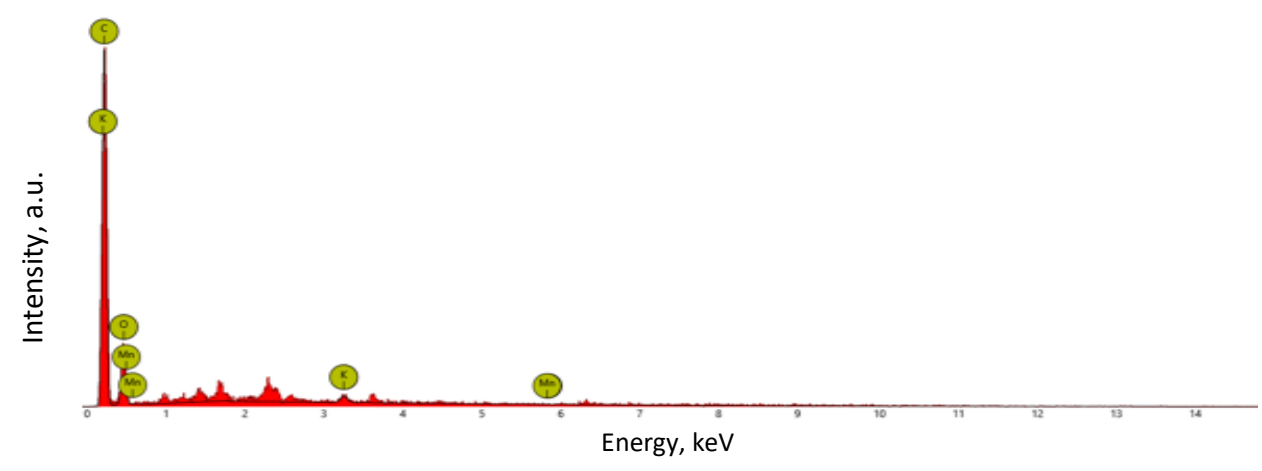

Figure 3. EDX analysis of aluminium specimen treated for 180 seconds in Manganate/fluoride/glycerol conversion coating at $30^{\circ} \mathrm{C}$

Aluminium may be derived from the coating as compounds formed from $\mathrm{Al}^{3+}$ generated during activation by $\mathrm{F}^{-}$species as well as from the substrate which is aluminum. Oxygen and manganese will generally be derived from the coating materials as well as other contaminants such as $\mathrm{K}$ and $\mathrm{S}$.

\section{Corrosion and adhesion performance}

To all intents and purposes, all the specimens' conversion coated were superior in performance to the 'bare' specimens on which incipient pits were resolvable with the naked eyes in addition to mounds of corrosion products which appeared whitish under the lacquer coatings. There were no obvious incidents of pitting on both the bare conversion coated and those with top coatings of lacquer after the exposure period of time.

For specimens immersed in sodium chloride solution, 'bare' aluminum specimens with and without lacquer coatings showed severe pitting corrosion over the immersion period. A typical example is displayed in Fig. 4, the scanning electron micrograph of the unscratched regions of 'bare' aluminum specimen with a top coating of lacquer. The micrograph portrays a relatively large pit at the top of the micrograph with corrosion products at the bottom of the micrograph.

The corrosion products, likely to have migrated from within the pit, where active pitting corrosion occurred are composed of hydrated aluminum hydroxides and/or oxides which were initially gellike, developed cracked morphologies during drying out. The EDX analysis in the region revealed the presence of $\mathrm{Al}, \mathrm{O}, \mathrm{Cl}$ and $\mathrm{Na}$ which indicated the presence of aluminum products contaminated or 
otherwise with chlorides which are known pitting agents of aluminum and its alloys. On the other hand, the unscratched regions of the conversion coated specimen with a top coating of lacquer, displayed in Fig. 5, did not show active pitted regions, however, a region at the top right corner of the micrograph, marked ' + ' revealed disaggregated materials which may be a flawed region of the composite conversion/lacquer coating where pitting corrosion may have initiated but propagation was hindered in one manner or the other.

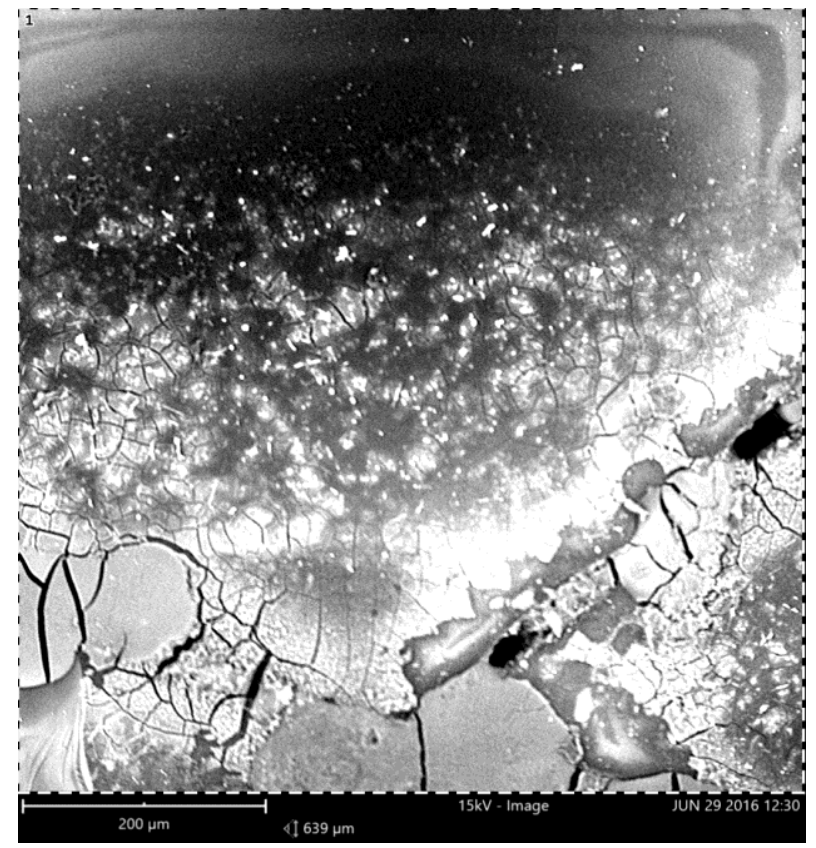

Figure 4. Scanning electron micrograph of lacquer coated 'bare' aluminum immersed in $1 \mathrm{M} \mathrm{NaCl}$ solution for $170 \mathrm{~h}$ at $30^{\circ} \mathrm{C}$.

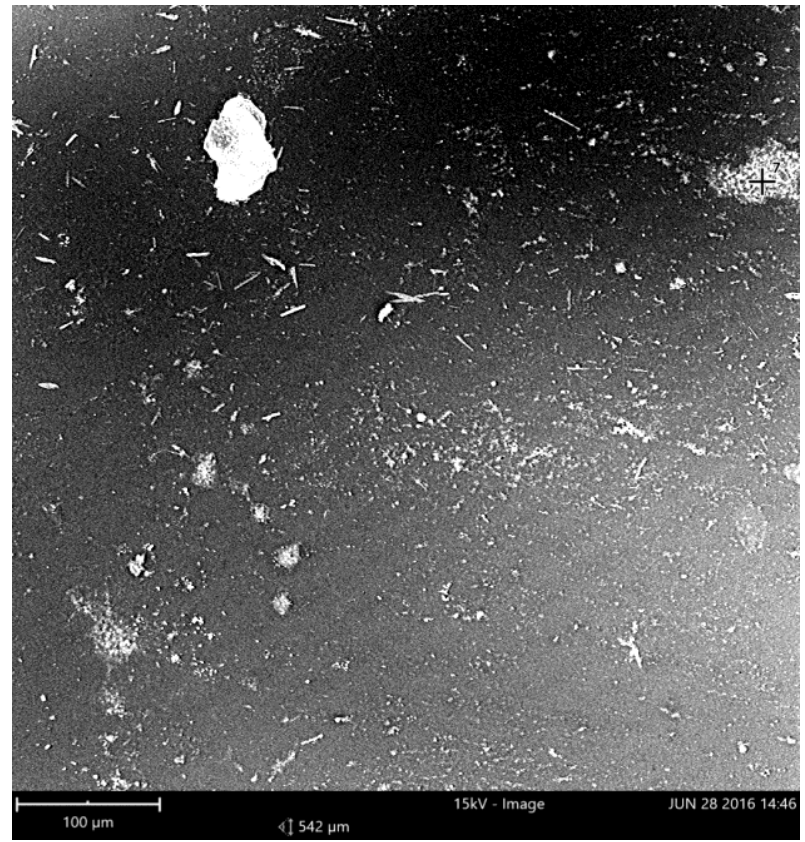

Figure 5. Scanning electron micrograph of conversion coated aluminum with a top coating of lacquer after immersion in $1 \mathrm{M} \mathrm{NaCl}$ solution for $170 \mathrm{~h}$ at $30^{\circ} \mathrm{C}$ after application of adhesion tests.

EDX spectra of spot analysis at this region, Fig. 6, revealed the presence of aluminum, manganese, oxygen, potassium and chloride. $\mathrm{Mn}, \mathrm{Al}, \mathrm{O}$ are derived from the conversion coating whereas the presence of $\mathrm{Cl}$ implied its corrosion activities at the flaw which led to production of disaggregated materials at the region.

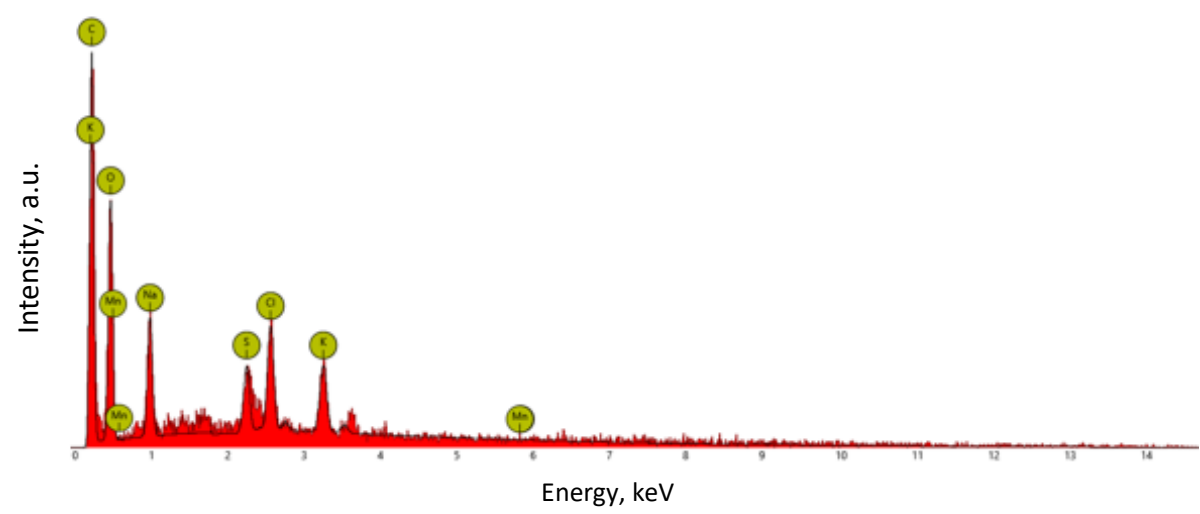

Figure 6. EDX spot analysis of the region marked ' + ' on the specimen conversion coated with a top coating of lacquer immersed in $1 \mathrm{M} \mathrm{NaCl}$ solution for $170 \mathrm{~h}$ at $30^{\circ} \mathrm{C}$ after adhesion tests.

Another interesting feature appeared as light material at the top left corner of the micrograph in Fig. 5, which from EDX analysis is composed of $\mathrm{Al}, \mathrm{Mn}, \mathrm{O}$ and $\mathrm{Cl}$ and may likewise be pitting corrosion products which had plugged the entrance to a pit. The presence of reducible $\mathrm{MnO}_{4}^{-}$in manganate 
coatings had been confirmed by Danilidis et al. [18]. Such anions in the vicinity of active pitting activities can effectively pick up the electrons generated from the aluminum substrate to form $\mathrm{MnO}_{2}$ mixed with aluminum compounds to give rise to such features on the specimen. From the foregoing analyses, it is obvious that the conversion coated specimens out-performed the 'bare' aluminum specimens in terms of corrosion resistance. As far as paint adhesion characteristics were concerned, paint delamination was not observed on the conversion coated specimen and the top coating of lacquer was not removed after the application of tape peeling adhesion tests. On the other hand, lacquer was easily removed from the 'bare' aluminum specimen.

\section{Conclusions}

The hybrid manganate/fluoride/glycerol conversion coating on aluminum is composed of $\mathrm{Mn}, \mathrm{Al}$ and $\mathrm{O}$ compounds and its surface morphology appeared rough on a microscopic scale.

The corrosion resistance and paint adhesion characteristics of the conversion coating as well as the conversion coating/lacquer composite on aluminum substrate were superior to those of 'bare' aluminum from natural and accelerated corrosion tests in $1 \mathrm{M} \mathrm{NaCl}$ solution.

During the course of this investigation, the surface morphologies and elemental compositions of specimens treated in manganate coating solutions with and without glycerol additions were compared. The cracked surface morphologies were similar however, the yield of $\mathrm{Mn}$ in the hybrid coating was higher than for the later.

Acknowledgements: The authors acknowledge Department of Mechanical Engineering, Covenant University, Ota, Ogun State, Nigeria, for the use of SEM/EDX facilities

\section{References}

[1] O. Lunder, Chromate free pretreatment of aluminium for adhesive bonding, PhD Thesis, Norges Teknisk-Naturvitenskapelige Universitet, (2003)

[2] S. Joshi, B. L. Treu, M. J. O'Keefe, W.G. Fahrenholtz, Journal of the Electrochemical Society, 158 (2011). 88-93

[3] C. S. Liang, Z. F. Lv, Y.L. Zhu, S.A. Xu, Surface Coatings Technology 249 (2014) 1-5

[4] H. R Asemani, P. Ahmadi, A. A Sarabi, H. Eivaz Mohammadloo, Progress in Organic Coatings 94 (2016) 18-27

[5] M. Oki, Journal of Applied Science and Environmental Management 11(2) (2007) 87-190

[6] W. Guixiang, Z. Milin, W. Applied Surface Science 258 (2012) 2648-2654

[7] S. Y Jian, Y. R. Chu, C. S. Liu, Corrosion Science 93 (2015)301-309

[8] A. E. Hughes, J. D. Gorman, T. D. Gorman, T. G.Harvey, A. Galassi, G. McAdam, Corrosion Science. 62 (9) 774-780

[9] M. Oubaha, P. C. R. Varma, B. Duffy, Z. M. Gasem, S. J. Hinder, Advances in Materials Physics and Chemistry.4 (2014) 75-84

[10] E. Gonzalez, J. Pavez, I. Azocar, J. H. Zagal, X. Zhou, F. Melo, G.E. Thompson, M.A. Páez, Electrochimica Acta 56 (2011) 7585-7595

[11] R. Buchheit, U S. Patent Nov. 14, 7, 135,075 B2 (2006)

[12] N. N. Vovodin, V.N. Balbyshev, M.S. Donley, Progress in Organic Coatings 52 (2005) 28-33

[13] M. Oki, Patent number, NG/P/2013/755, April (2014)

[14] Japanese Industrial Standard Testing Methods for Paints JISK 5400, Japanese Standards Association, Tokyo, Japan, (1990).

[15] M. F. Abd Rabbo, J. A. Richardson, G. C. Wood, Corrosion Science 18(1) (1978) 117-123

[16] R. C. Furneaux, G. E. Thompson, G. C. Wood, Corrosion Science 19(1) (1979) 63-71

[17] S. A. Kulinich, M. Farzaneh, X. W. Du, Inorganic Materials 43(9) (2007) 956-963 
[18] I. Danilidis, J. A. Hunter, G. M. Scamans, J. M.Sykes, Corrosion Science 49(3) (2007) 15571569

[19] K. Asami, M. Oki, G. E. Thompson, G. C. Wood, V Ashworth, Electrochimica Acta 32(2) (1987) 337-343

[20] C. S. Liang, Z. F. Lv, Y. L. Zhu, S. A. Xu, Surface and Coatings Technology 249 (2014) 1-5

[21] M. L. Zheludkevich, I. Miranda Salvadob, M. G. S. Ferreira, Journal of Materials Chemistry 15 (2005) 5099-5111

[22] M. Oki, Materials Science 2013, Article ID572379, DOI: 10.115/2013/572379

(C)2017 by the authors; licensee IAPC, Zagreb, Croatia. This article is an open-access article distributed under the terms and conditions of the Creative Commons Attribution license (http://creativecommons.org/licenses/by/4.0/) 